Research Journal of Medical Sciences 6 (1): 7-12, 2012

ISSN: $1815-9346$

(C) Medwell Journals, 2012

\title{
Comparative Effects of Thiopentone and Propofol on Seizure Duration and Recovery Following Modified Electroconvulsive Therapy in Nigerians
}

\author{
${ }^{1}$ F.O. Omosofe, ${ }^{1}$ B.O. Bolaji, ${ }^{1}$ I.K. Kolawole and ${ }^{2}$ A.B. Makanjuola \\ ${ }^{1}$ Department of Anaesthesia, ${ }^{2}$ Department of Behavioural Sciences, \\ University of Ilorin Teaching Hospital, Ilorin, Nigeria
}

\begin{abstract}
The clinical efficacy of Electroconvulsive Therapy (ECT) depends on the induction of generalized cerebral seizure activity. One goal of anaesthesia for ECT is to relax the voluntary muscles with the aim of reducing convulsive activity and thereby minimize the risk of physical harm to the patient. An anaesthetic induction agent with rapid recovery profile will therefore be most suitable for modified ECT. The aim of the study was to compare the seizure duration and recovery profile of thiopentone and propofol following modified electroconvulsive therapy. In a prospective, randomized, double-blind study, sixty consecutive patients scheduled for ECT were randomly allocated into the unmodified, thiopentone and propofol groups with twenty in each group. Anaesthesia was induced with $1 \mathrm{mg} \mathrm{kg}^{-1}$ of Propofol (PG) and $5 \mathrm{mg} \mathrm{kg}^{-1}$ of Thiopentone (TG) and intravenous suxamethonium chloride was administered at a dose of $0.5 \mathrm{mg} \mathrm{kg}^{-1}$. Anaesthesia was not administered to the patients in the Unmodified Group (UG) which served as control. The patients' heart rate, blood pressure and arterial oxygen saturation were monitored during the procedure. The duration of seizure and the time taken to gain full recovery in the groups were also compared. The shortest mean seizure duration was recorded in $\mathrm{PG}(23.30 \pm 3.06 \mathrm{sec})$ compared with $34.20 \pm 4.35 \mathrm{sec}$ in $\mathrm{UG}$ and $28.25 \pm 3.58 \mathrm{sec}$ in $\mathrm{TG}$. The duration was significantly less in $\mathrm{PG}$ than $\mathrm{TG}(\mathrm{p}=0.008)$. The mean time to eye opening and obeying command was significantly less in $\mathrm{PG}$ than $\mathrm{TG}$ ( $\mathrm{p}=0.009$ and 0.006 , respectively) but time to full orientation was not significantly different $(\mathrm{p}=0.080)$. Propofol produced a significant reduction in seizure duration but it is not better than thiopentone with regards to recovery characteristics after ECT.
\end{abstract}

Key words: Modified electroconvulsive therapy, seizure duration, recovery, propofol, thiopentone, Nigeria

\section{INTRODUCTION}

The clinical efficacy of ECT depends on the induction of generalized cerebral seizure activity. The hallmark of generalized cerebral seizure activity is the tonic-clonic or grand mal convulsion occurring on both sides of the body. Electroconvulsive Therapy (ECT) is a safe and effective treatment (Abrams, 1997; Reid et al., 1998). The risk of mortality with ECT and associated anaesthesia is about 10 times lower than that with childbirth (Abrams, 1997) and compares favourably with the risk associated with general anaesthesia alone (Fink, 1997). Musculoskeletal events comprise the commonest and the most distressing morbidity associated with unmodified ECT. They include compression fractures of the spine, fractures of long bones, dislocation of shoulder and temporomandibular joints, injury to muscles, tendons and ligaments.

The early ECTs as introduced by Cerlett and Bini in 1937 were unmodified that is not implemented under sedation, anaesthesia, neuromuscular blockade nor supplementary oxygenation and no ventilation administered (Selvin, 1987). From early 1960s, modified ECT under anaesthesia with neuromuscular blockade has become worldwide standard. One goal of anaesthesia for ECT is to relax the voluntary muscles with the aim of reducing convulsive activity to minimize the risk of physical harm to the patient. An induction agent with rapid recovery profile is most suitable for modified ECT. Several anaesthetics have been used for ECT. Methohexitone and thiopentone have been commonly used. The advent of propofol added to the number of agents readily available for ECT and it is increasing in popularity (Fear et al., 1994; Tan and Lee, 2009). The effects of these agents on seizure threshold, haemodynamic changes and recovery profile post ECT have been compared by various researchers in the America and European worlds (Fear et al., 1994; Geretsegger et al., 2007; Tan and Lee, 2009). Studies in Nigeria are rather rare. Lim et al. (1996) have however, compared the haemodynamic effects of thiopentone with methohexitone in Nigeria while Ogunbiyi and Branch

Corresponding Auhtor: B.O. Bolaji, Departments of Anaesthesia, University of Ilorin Teaching Hospital, Ilorin, Nigeria 
(1999) studied the complications arising from substitution of suxamethonium with mivacurium. Ihezue and Ebigbo (1981) determined the status and practice of ECT in Enugu. Odejide et al. (1987) in their study considered the extent of use of ECT in Nigeria. No study in Nigeria to date has however, compared the seizure duration and recovery profile of thiopentone with propofol in electroconvulsive therapy hence, the need for this study in this environment.

This study was carried out to determine and to compare the effects of propofol with thiopentone on seizure duration and recovery profiles and to compare the observed changes with those of unmodified ECT in Nigerian patients.

\section{MATERIALS AND METHODS}

The study setting: The study was conducted in two hospitals in Nigeria; University of Ilorin Teaching Hospital and Federal Neuropsychiatric Hospital (FNPH), Aro, Abeokuta. The University of Ilorin Teaching Hospital (UITH) Ilorin is located in the North central region of Nigeria. It is a referral centre for patients in Kwara, Kogi, Niger, part of Oyo and Ekiti states. The other hospital is the Federal Neuropsychiatric Hospital, Aro, (FNPH) Abeokuta which is located in the South Western part of Nigeria. Each of the hospitals has a bed capacity of over 500 and are both service, training and research centres.

Following institutional ethic's approval, sixty adults patients scheduled for Electroconvulsive Therapy (ECT) in UITH, Ilorin and FNPH, Abeokuta in Nigeria were enrolled into the study. Inclusion criteria were: Adult patients above 18 years of age who were diagnosed with psychotic disorders or were being managed for depression, patients with American Society of Anesthesiologists (ASA) classification not greater than II and patients on admission. Excluded from the study were patients below 18 years of age, patients with intracranial lesion with associated evidence of raised intracranial pressure, previous history of myocardial infarction, porphyria, glaucoma, patients in whom face mask ventilation was anticipated to be difficult (e.g., edentulous patients), family history of malignant hyperthermia, patients who refused the procedure and patients with ASA greater than II.

Sampling method: With the use of ballot papers, all consecutive consenting patients were assigned into three groups ( 20 for the unmodified, 20 for thiopentone and 20 for propofol groups) until a calculated sample size of 60 (Using the average number of ECT per year in the two institutions) was obtained.
Administration of anaesthesia and ECT: Routine pre-anaesthetic review was carried out on all the patients the night before administration of ECT. Patients were clinically examined and their age, sex, ASA, height, weight and psychomedication were documented. Informed consent was obtained from the patients' relatives after thorough explanation of the procedure. All patients were fasted overnight and no premedication was given. Drugs for resuscitation (Adrenaline, atropine, sodium bicarbonate, etc.) were made available in the ECT room while the suctioning and anaesthesia machines were checked and found to be functional before administration of electroconvulsive therapy.

In the ECT room, all the patients were connected to a Nellcor Puritan BennettNPB 4000 multiparameter patient monitor. The baseline Heart Rate (HR), Systolic Blood Pressure (SBP), Mean Arterial Pressure (MAP) and Diastolic Blood Pressure (DBP) were taken and recorded pre ECT. Arterial oxygen saturation and the electrocardiogram were monitored continuously. Intravenous access was secured with size $18 \mathrm{G}$ cannula for drug and fluid administration. All patients in the modified groups had a standard general anaesthesia. After $3 \mathrm{~min}$ of preoxygenation with $100 \%$ oxygen, anaesthesia was induced with propofol, $1 \mathrm{mg} \mathrm{kg}^{-1}$ in the propofol group and $5 \mathrm{mg} \mathrm{kg} \mathrm{mg}^{-1}$ of thiopentone in the thiopentone group. This was followed by intravenous administration of $0.5 \mathrm{mg} \mathrm{kg}^{-1}$ of suxamethonium chloride. Patients were ventilated briefly with $100 \%$ oxygen via a face mask using a Bain breathing system as soon as fasciculation subsided. Bite block was inserted to protect the tongue and subsequently the patients were electro shocked for $2 \mathrm{sec}$ using Ectonustion constant current ECT Apparatus series 5B manufactured by Ectron Ltd., Knap Close, Letchwork, England.

In the immediate post ECT periods, patients were ventilated with $100 \%$ oxygen via face mask connected through a Bain circuit to the anaesthesia machine until spontaneous respiration resumed. Patients in the unmodified group were preoxygenated with $100 \%$ oxygen for $3 \mathrm{~min}$ through a face mask before ECT. Bite block was inserted into the mouth to protect the tongue. All patients were draped from shoulder to the ankles using a blanket. Thereafter, patients were electro-shocked. Medical assistants gently held the patients down while the seizures lasted. Seizure duration was taken from the moment the tonic phase of convulsion was seen just after the shock was administered to the end of seizure using a stop watch. The Heart Rate (HR), SBP, MAP and DBP were recorded every $5 \mathrm{~min}$ till recovery. Patients were also ventilated post ECT with $100 \%$ oxygen until spontaneous respiration resumed and then transferred in the left lateral position to the recovery room. 
Recovery time was taken as time from loss of consciousness at induction of anaesthesia to orientation. Time taken for spontaneous eye opening and obeying command were also recorded. The mean values of seizure duration, time for eye opening, obeying command and orientation for each group were determined and compared.

Data analysis: Data were analyzed using Epi-info version 6.2 computer software. Frequency tables were generated and the means compared using the student's t-test while the proportions were compared using the $\chi^{2}$-tests. Level of statistical significance was set at $\mathrm{p}<0.05$.

\section{RESULTS AND DISCUSSION}

Data were obtained from the three groups of sixty psychiatric patients scheduled for ECT. The groups were well matched in their demographic data as shown in Table 1.

Seizure duration: As shown in Table 2 the longest mean duration of seizure was seen in the unmodified group $(34.20 \pm 4.35 \mathrm{sec})$, propofol group had the shortest duration of seizure $(23.30 \pm 3.06 \mathrm{sec})$ while the thiopentone group had a duration of $28.25 \pm 3.58 \mathrm{sec}$. Seizure duration was reduced significantly by $17.39 \%$ with thiopentone $(\mathrm{p}=0.000)$ and $31.87 \%$ with propofol $(\mathrm{p}=0.000)$ when both were independently compared with the unmodified group. The difference in the duration of seizure was significantly shorter by $4.95 \mathrm{sec}$ in the propofol group as compared with the thiopentone group (p-value of 0.008).

Table 1: Demographic characteristics of the three groups

\begin{tabular}{lllll}
\hline & Groups: Mean \pm SD & & \\
& - & & \\
Demography & Age (years) & Weight $(\mathrm{kg})$ & Height $(\mathrm{cm})$ & Sex: M/F \\
\hline Unmodified & $28.70 \pm 5.66$ & $59.45 \pm 7.39$ & $164.79 \pm 7.97$ & $14 / 6$ \\
Thiopentone & $29.45 \pm 5.96$ & $61.65 \pm 8.26$ & $169.00 \pm 5.79$ & $12 / 8$ \\
p-value & 0.293 & 0.060 & 0.130 & - \\
Unmodified & $28.70 \pm 5.66$ & $59.45 \pm 7.39$ & $164.79 \pm 7.97$ & $14 / 6$ \\
Propofol & $29.30 \pm 5.35$ & $63.25 \pm 6.65$ & $166.60 \pm 7.06$ & $13 / 7$ \\
p-value & 0.530 & 0.060 & 0.069 & - \\
Thiopentone & $29.45 \pm 5.96$ & $61.65 \pm 8.26$ & $169.00 \pm 5.79$ & $12 / 8$ \\
Propofol & $29.30 \pm 5.35$ & $63.25 \pm 6.65$ & $166.60 \pm 7.06$ & $13 / 7$ \\
p-value & 0.307 & 0.072 & 0.190 & - \\
\hline
\end{tabular}

Table 2: Comparison of the mean seizure duration in the three groups (Unmodified, thiopentone and propofol)

\begin{tabular}{|c|c|c|c|c|}
\hline Groups & $\begin{array}{c}\text { Seizure } \\
\text { duration }(\mathrm{sec})\end{array}$ & $\begin{array}{r}\text { Differences } \\
\text { in group }(\mathrm{sec})\end{array}$ & Change (\%) & $\mathrm{p}$-value \\
\hline Unmodified & $34.20 \pm 4.35$ & 5.95 & 17.39 & 0.000 \\
\hline Thiopentone & $28.35 \pm 3.58$ & - & - & - \\
\hline Unmodified & $34.20 \pm 4.35$ & 10.90 & 31.87 & 0.000 \\
\hline Propofol & $23.30 \pm 3.06$ & - & - & - \\
\hline Thiopentone & $28.35 \pm 3.58$ & 4.95 & 17.50 & 0.008 \\
\hline Propofol & $23.30 \pm 3.06$ & - & - & - \\
\hline
\end{tabular}

Recovery: Table 3 shows the mean recovery characteristics in the three groups. The mean time taken to open eyes was longest in the thiopentone group $(9.30 \mathrm{~min} \pm 2.20 \mathrm{SD})$ and shortest in the unmodified group ( $5.80 \mathrm{~min} \pm 1.91 \mathrm{SD}$ ). Patients in the propofol group opened their eyes after $7.40 \mathrm{~min} \pm 1.98 \mathrm{SD}$. Time to eye opening was significantly longer by $3.50 \mathrm{~min}$ in the thiopentone group than in the unmodified group $(\mathrm{p}=0.000)$. It was also significantly longer in the propofol group by $1.60 \mathrm{~min}$ compared with the unmodified group $(\mathrm{p}=0.014)$.

Time taken by patients in the unmodified group to obey command was significantly shorter by $2.10 \mathrm{~min}$ than in the thiopentone group ( $\mathrm{p}=0.006)$ while no significant difference was seen in obeying command between the unmodified group and the propofol group though it was shorter by $0.65 \mathrm{~min}$ in the unmodified group $(\mathrm{p}=0.336)$. There was however, a statistically significant shorter time of $1.45 \mathrm{~min}$ in obeying command in the propofol group than in the thiopentone group $(\mathrm{p}=0.006)$. Time taken to attain full orientation was longest in the thiopentone group (14.20 $44.35 \mathrm{~min}$ ) and shortest in the unmodified group (11.55 $\pm 2.82 \mathrm{~min}$ ). Patients in the propofol group had full orientation at $12.25 \pm 1.92 \mathrm{~min}$.

The only statistically significant mean difference in time to full orientation in the three groups was recorded between the thiopentone group and the unmodified group; it was longer by $2.65 \mathrm{~min}$ in the thiopentone group $(\mathrm{p}=0.001)$. The shortest recovery time was recorded in the unmodified group while the longest recovery time occurred in the thiopentone group. No significant mean differences in recovery times were seen between propofol and the unmodified group $(\mathrm{p}=0.410)$ and between thiopentone and propofol groups $(\mathrm{p}=0.080)$.

Seizure duration is an extensively studied and controversial indicator of treatment in electroconvulsive therapy. The clinical efficacy of ECT depends on the

Table 3: Comparison of the mean recovery characteristics in the unmodified, thiopentone and propofol groups

\begin{tabular}{lccc}
\hline & Groups & & \\
& - & & \\
Recovery & Eye opening (min) & Obey (min) & Orientation (min) \\
\hline Unmodified & $5.800 \pm 1.91$ & $9.450 \pm 2.69$ & $11.550 \pm 2.82$ \\
Thiopentone & $9.300 \pm 2.20$ & $11.550 \pm 2.74$ & $14.200 \pm 4.35$ \\
Difference & 3.500 & 2.100 & 2.650 \\
p-value & 0.000 & 0.006 & 0.001 \\
Unmodified & $5.800 \pm 1.91$ & $9.450 \pm 2.69$ & $11.550 \pm 2.82$ \\
Propofol & $7.400 \pm 1.98$ & $10.100 \pm 1.68$ & $12.250 \pm 1.92$ \\
Difference & 1.600 & 0.650 & 0.700 \\
p-value & 0.014 & 0.336 & 0.410 \\
Thiopentone & $9.300 \pm 2.20$ & $11.550 \pm 2.74$ & $14.200 \pm 4.35$ \\
Propofol & $7.400 \pm 1.98$ & $10.100 \pm 1.68$ & $12.250 \pm 1.92$ \\
Difference & 1.900 & 1.450 & 1.950 \\
p-value & 0.009 & 0.006 & 0.080 \\
\hline
\end{tabular}


induction of generalized cerebral seizure activity. This can be monitored by EEG or visible convulsive activity of (Tonic-clonic convulsion) affecting muscles of the limbs on both sides of the body. In this own setting where the EEG was not readily available, tonic-clonic convulsion was used to monitor seizure activity as recommended by Whitehouse and Scott (2004). The length in time of the cerebral seizure activity of the tonic-clonic convulsion is not related to clinical efficacy (Sackeim et al., 1991; Weiner et al., 1991). However, if the convulsive activity is $<15 \mathrm{sec}$ or EEG activity $<25 \mathrm{sec}$ then, the therapeutic effect of the ECT may be doubtful. Intravenous anaesthetics produce unconsciousness while the barbiturate group in addition also reduce convulsive activity. An ideal anaesthetic for ECT should have characteristics that include rapid induction, rapid recovery and little or no anticonvulsant effect (To avoid reduction of seizure duration).

In this study, the unmodified group had the longest duration of seizure while propofol had the shortest. Previous studies have compared the effect of propofol on seizure duration with that of barbiturates which have long history of use in ECT (Boey and Lai, 1990; Ingram et al., 2007). These studies demonstrated that propofol anaesthesia reduced seizure duration compared with thiopentone. The $17.50 \%$ shorter seizure duration observed in propofol group in the present study was comparable to a previous report by Boey and Lai (1990). Fredman et al. (1994) also showed that the use of propofol was associated with significantly shorter motor and EEG seizure duration. Some cross over trials showed up to $25 \%$ reduction in seizure duration when propofol was compared with methohexitone (Rampton et al., 1988; Simpson et al., 1988). Three other studies however found no significant difference in efficacy between methohexitone and propofol (Fear et al., 1994; Malsh et al., 1994; Kirbby et al., 1995).

A study of propofol and etomidate suggested a longer course of treatment was required with propofol compared with etomidate i.e., propofol was less efficacious (Patel et al., 2006). They observed that patients who received propofol had longer acute courses of ECT and consequently longer and costlier in patient stays. Since, it is required that seizure duration should be $>20 \mathrm{sec}$ for ECT to be efficacious (Scott and Boddy, 2002), the result of the present study which showed that propofol at a dose of $1 \mathrm{mg} \mathrm{kg}^{-1}$ produced a mean seizure duration of $23.20 \mathrm{sec}$ should not impair the therapeutic efficacy of ECT in the patients. The reduction in seizure duration is dose dependent and at a dose $>1 \mathrm{mg} \mathrm{kg}^{-1}$ the reduction becomes more significant with the therapeutic effect of ECT becoming severely impaired (Rampton et al., 1989). However, one psychiatric report concluded that the efficacy of ECT using propofol did not differ significantly from those using barbiturate (Geretsegger et al., 1998). Boiteux et al. (1997) also observed that seizure reduction capacity did not differ when thiopentone was compared to methohexitone. Their conclusion may have arisen as a result of the small population size used in their study. Propofol is a better alternative to barbiturates for the treatment of patients with excessive long seizures and/or severe nausea and vomiting which is common in adolescent patients (Esmaili and Malek, 2007). This is because propofol has tendencies for reducing seizures in ECT and it has antiemetic effects.

Recovery after ECT: An appropriate anaesthetic agent must have a rapid onset of action and rapid recovery profile. Fastest recovery period in terms of eye opening and full orientation was seen in the unmodified group. The recovery characteristic in propofol group was found to be comparable to that in the unmodified group. Recovery was significantly prolonged in the thiopentone group compared with the unmodified group.

No significant differences in recovery was seen when thiopentone was compared with propofol. This could have been as a result of the fact that recovery after convulsion (Post Otal recovery) may be delayed and then, mask the expected early recovery characteristics of propofol. Early recovery with propofol is seen in other procedures. A day case study of gynaecological procedures by Kushimo et al. (1997) showed that propofol had a more rapid recovery profile than thiopentone.

In a study of ECT however, Matters et al. (1995) suggested that the more rapid recovery rates noted with propofol in other procedures are not evident after electrically induced seizures. This agreed with the present study in which no significant difference was seen when recovery profile (Full orientation) in the propofol group was compared with that in the thiopentone group.

Sevoflurane has been found to compare favourably with thiopental in terms of haemodynamics, post treatment orientation and time to first breath in a study (Rasmussen et al., 2007). Similar situation was also found by another study that compared sevoflurane with propofol (Toprak et al., 2005). This shows that recovery with sevoflurane after ECT is similar to the recovery profiles seen in thiopentone and propofol. A previous 
study has however, observed that propofol has better recovery profiles than thiopentone in ECT (Zaidi and Kahn, 2000).

\section{CONCLUSION}

Propofol at a dose of $1 \mathrm{mg} \mathrm{kg}^{-1}$ caused a significant reduction in seizure duration compared with the thiopentone and unmodified group. The mean seizure duration was within acceptable limits for effective ECT. Though time to full orientation was shorter with propofol, no significant difference was found in the time to full orientation between the two induction agents.

\section{ACKNOWLEDGEMENTS}

The researchers hereby acknowledge the Hospital Management of the University of Ilorin Teaching Hospital and Federal Neuropsychiatric Hospital, Abeokuta both in Nigeria for ethical clearance for this research.

\section{REFERENCES}

Abrams, R., 1997. The mortality rate with ECT. Convuls Ther., 13: 125-127.

Boey, W.K. and F.O. Lai, 1990. Comparison of propofol and thiopentone as anaesthetic agents for electroconvulsive therapy. Anaesthesia, 45: 623-628.

Boiteux, J., L. Roubaud, N. Gendelet, S. Nezelof and N. Vittouris et al., 1997. Indications for electroconvulsive therapy. Encephale, 23: 21-26.

Esmaili, T. and A. Malek, 2007. Electroconvulsive Therapy $(\mathrm{ECT}$ ) in a six year old girl suffering from major depressive disorder with catatonic features. Eur. Child Adolesc. Psychiatry, 16: 58-60.

Fear, C.F., S. Littlejohns S., E. Rouse and P. McQuail, 1994. Propofol anaesthesia in electroconvulsive therapy: Reduced seizure duration may not be relevant. Br. J. Pshychiatry, 165: 506-509.

Fink, M., 1997. Convulsive Therapy: Theory and Practice. Raven Press, New York, USA., ISBN: 0890042217, Pages: 308.

Fredman, B., J. D'Etienne, J. Smith, M.M. Hussain and P.F. White, 1994. Anaesthesia for electroconvulsive therapy; effects of propofol and methohexital on seizure activity and recovery. Anesth. Analg., 79: 75-79.

Geretsegger, C., E. Rochowanski, C. Kartnig and A.F. Unterrainer, 1998. Propofol and methohexital as anaesthetic agents for Electroconvulsive Therapy (ECT): A comparison of seizure quality measures and vital signs. J. ECT, 14: 28-35.
Geretsegger, C., M. Nickel, B. Judendorfer, E. Rochowanski, E. Novak and W. Aichhorn, 2007. Propofol and methohexital as anesthetic agents for electroconvulsive therapy: A randomized, doubleblind comparison of electroconvulsive therapy seizure quality, therapeutic efficacy and cognitive performance. J. ECT, 23: 239-243.

Ihezue, H.U. and P.O. Ebigbo, 1981. Present status and practice of electroconvulsive therapy at the psychiatric hospital, Enugu, Nigeria. Acta Psychiatr. Scand., 63: 325-332.

Ingram, A., I. Schweitzer, C.H. Ng, M.M. Saling and G. Savage, 2007. A comparison of propofol and thiopentone use in electroconvulsive therapy: Cognitive and efficacy effects. J. ECT, 23: 158-162.

Kirbby, K.C., W.G. Beckett, R.M. Matters and T.E. King, 1995. Comparison of propofol and methohexitone in anaesthesia for ECT: Effect on seizure duration and outcome. Aust. N. Z. J. Psychiatry, 29: 299-303.

Kushimo, O.T., N. Merah and D.J.O. Ffoulkes-Crabbe, 1997. Comparison of propofol with thiopentone induction of anesthesia for gynaecological day surgery. Afr. J. Anaesth. Intensive Care, 3: 20-26.

Lim, S.K., W.L. Lim, and E.O. Elegbe, 1996. Comparison of propofol and methohexitone as an induction agent in anaesthesia for electroconvulsive therapy. West Afr. J. Med., 15: 186-189.

Malsh, E., I. Gratz, S. Mani, C. Backup, S. Levy and E. Allen, 1994. Efficacy of electroconvulsive therapy after propofol and methohexital anaesthesia. Convuls Ther., 10: 212-219.

Matters, R.M., W.G. Beckett and K.C. Kirkby, 1995. Recovery after electroconvulsive therapy: A comparison of propofol with methohexitone anesthesia. Br. J. Anesth., 75: 297-300.

Odejide, A.O., J.U. Ohaeri and B.A. Ikuesan, 1987. Electroconvulsive therapy in Nigeria. Convuls Ther., 3: 31-39.

Ogunbiyi, O.A. and K.G. Branch, 1999. Mivacurium apnoea; A trap for the unwary. Int. J. Clin. Pract., 53: 154-155.

Patel, A.S., C. Gorst-Unsworth, R.M. Venn, K. Kelley and Y. Jacob, 2006. Anaesthesia for electroconvulsive therapy: A retrospective study comparing etomidate and propofol. J. ECT, 22: 179-183.

Rampton, A.J., R.M. Griffin, C.S. Stuart, J.J. Durcan, N.C. Huddy and M.A. Abbott, 1989. Comparison of propofol and methohexitone for electroconvulsive therapy: Effects on hemodynamic responses and seizure duration. Anesthesiology, 70: 412-417.

Rampton, A.J., R.M. Griffin, J.S. Durcan and C.S. Stuart, 1988. Propofol and electroconvulsive therapy. Lancet, 1: 296-297. 
Rasmussen, K.G., D.R. Laurila, B.M. Brady, C.L. Lewis and K.D. Niemeyer et al., 2007. Anaesthesia outcome in a randomized double blind trial of sevoflurane and thiopental for induction of general anaesthesia in electroconvulsive therapy. J. ECT, 23: 236-238.

Reid, W.H., S. Keller, M. Leatherman and M. Mason, 1998. ECT in Texas: 19 months of mandatory reporting. J. Clin. Psychiatry, 59: 8-13.

Sackeim, H.A., D.P. Devanand and J. Prudic, 1991. Stimulus intensity, seizure threshold and seizure duration: Impact on the efficacy and safety of electroconvulsive therapy. Psychiatr Clin. North Am., 14: 843-844.

Scott, A. and H. Boddy, 2002. Induction agents in electroconvulsive therapy a comparison of methohexitone and propofol. Psychiatric Bull., 26: $455-457$.

Selvin, B.L., 1987. Electroconvulsive therapy. Anesthesiology, 67: 367-385.
Simpson, K.H., P.J. Halsall, C.M.E. Carr and K.G. Stewart, 1988. Propofol reduces seizure duration in patients having anaesthesia for electroconvulsive therapy. $\mathrm{Br}$. J. Anaesth., 61: 343-344.

Tan, H.L. and C.Y. Lee, 2009. Comparison between the effects of propofol and etomidate on motor and electroencephalogram seizure duration during electroconvulsive therapy. Anaesth. Intensive Care, 37: 807-814

Toprak, H.I., E. Gedik, Z. Begec, E. Ozturk and B. Kaya, 2005. Sevoflurane as an alternative anaesthetics for electroconvulsive therapy. J. ECT, 21: 108-110.

Weiner, R.D., C.E. Coffey and A.D. Krystal, 1991. The monitoring and management of electrically induced seizures. Psychiatr Clin. North Am., 14: 845-869.

Whitehouse, A.M. and I.F. Scott, 2004. Monitoring Seizure Activity. In: The ECT Handbook, Scott, A.I.F. (Ed.). 2nd Edn. Royal College of Psychiatrists, London, UK., pp: 159-169.

Zaidi, N.A. and F.A. Kahn, 2000. Comparison of thiopental sodium and propofol for electroconvulsive therapy. J. Pak. Med. Assoc., 50: 60-63. 